\title{
Effect on mydriasis of modifying the volume of phenylephrine drops
}

\author{
E W Craig, P G Griffiths
}

\begin{abstract}
The cardiovascular effects of topically administered phenylephrine $10 \%$ are well known and can be minimised by reducing the concentration of drops administered. By modifying the dimensions of the dropper tip we reduced the volume of the drops administered, and therefore the total dose of phenylephrine, without altering the concentration. No difference in the mydriasis produced by drops of small and normal volume could be detected. Since a smaller dose of phenylephrine is administered with smaller drops, the risk of systemic side effects could be reduced by modifying the tips of eyedroppers.
\end{abstract}

The existence of systemic side effects from topically administered drugs is well recognised. Particular problems arise with topical B blockers such as timolol, and with phenylephrine, a commonly used mydriatic. Several different adverse reactions have been reported following topical ocular administration of phenylephrine $10 \%$. These include severe hypertension, subarachnoid haemorrhage, ventricular arrhythmias, and myocardial infarction. ${ }^{1}$ The dose of phenylephrine administered can be reduced by $2 \cdot 5 \%$. We adopted an alternative approach of using eyedrops of the same concentration, but reduced volume, delivering a smaller total dosage.

Department of Ophthalmology, Newcastle General Hospital, Newcastle upon Tyne

EW Craig

P G Griffiths

Correspondence to:

P G Griffiths, FRCS

Department of

Ophthalmology, Newcastle

General Hospital, Westgate

General Hospital, Westgate

Road, New.

Accepted for publication

4 October 1990

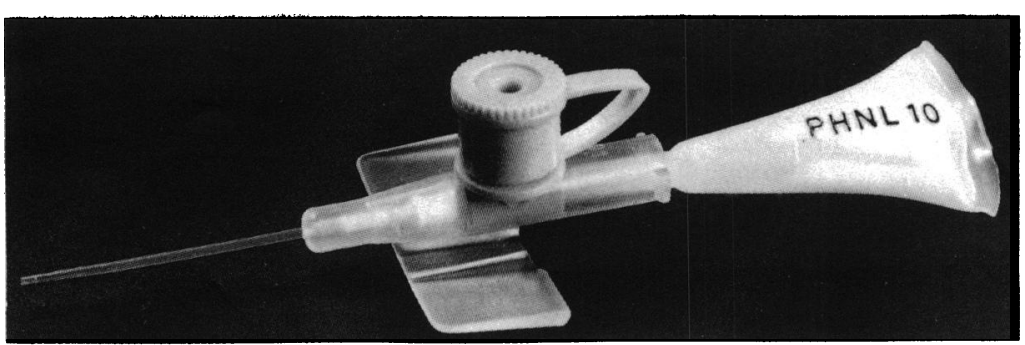

Figure 1 Showing attachment of 22 gauge cannula to a Minim of phenylephrine. time. It is assumed that the drops the same density as water and the weight in milligrams can be directly converted to volume in microlitres.

Reduced volume drops were produced by means of a $22 \mathrm{G}$ Venflon intravenous cannula which was attached to the end of a Minim after removal of the central stylette (Fig 1). The using more dilute drops such as phenylephrine

volume of the drop obtained was determined as described previously.

Pupil size was determined photographically. The subjects had their left pupil photographed while holding a millimetre scale on the lower lid within the field of view of the camera. The size of the pupil could then be determined on the projected image of colour slides, since the magnification factor would be the same for the pupil and the scale. The measurements were made without knowing what sized drop had been administered.

All photographs were taken at a constant level of illumination while the subject focused on letters at $3 \mathrm{~m}$ distance to ensure a constant amount of accommodation. Ametropes were excluded because magnification factors would be introduced when photographing through a spectacle lens. Informed consent was obtained from 20 healthy volunteers who had their left pupil photographed before receiving a small or a large drop, and a second photograph was taken one hour later. Half of the subjects received a small drop first and half received a large drop first; an interval of one week was left between tests.

\section{Results}

The normal volume of drops from Minims of phenylephrine $10 \%$ was 30 (SD4) $\mu$ l. Attaching a $22 \mathrm{G}$ Venflon intravenous cannula reduced the drop volume to 10 (SD2) $\mu \mathrm{l}$.

Most subjects commented that the smaller drops caused much less discomfort and were not always even aware that they had been instilled. The results are summarised in Table 1. The mean pupillary dilatation produced by normal sized drops was $3.6(\mathrm{SD} \mathrm{1.2}) \mathrm{mm}$ and the mean pupillary dilatation from small drops was $3 \cdot 7$ (SD 0.9) $\mathrm{mm}$. The small difference between these figures is not statistically significant $(t>1$, $\mathrm{df}=19, \mathrm{p}>0 \cdot 1)$.

\section{Discussion}

Phenylephrine is a powerful sympathomimetic drug which is an almost pure $\alpha$ receptor agonist. Systemically administered phenylephrine leads to peripheral vasoconstriction, resulting in increased systolic and diastolic blood pressure and reflex bradycardia. Heathe and Giete $^{2}$ have shown that topical phenylephrine $10 \%$ increases blood pressure by up to $10 \mathrm{mmHg}$ in $2 \%$ of subjects. Despite this, reports of side effects in the adult population are rare in view of its widespread use, though recently myocardial infarction was described following its intraoperative use. ${ }^{3}$

The normal volume of the tear film is $7 \mu \mathrm{l}-$ namely, $1 \mu \mathrm{l}$ in the precorneal tear film and $3 \mu \mathrm{l}$ in 
Table 1 Pupillary dilatation produced by $30 \mu \mathrm{m}$ and $10 \mu \mathrm{m}$ eyedrops

\begin{tabular}{|c|c|c|c|c|c|c|}
\hline \multirow[b]{2}{*}{ Subject } & \multicolumn{3}{|c|}{ Pupil size, mm } & \multicolumn{3}{|c|}{ Pupil size, mm } \\
\hline & Pre-drop & Post $-30 \mu l$ drop & Difference & Pre-drop & Post $-10 \mu \mathrm{l}$ & Difference \\
\hline $\begin{array}{r}1 \\
2 \\
3 \\
4 \\
5 \\
6 \\
7 \\
7 \\
8 \\
9 \\
10 \\
11 \\
12 \\
13 \\
14 \\
15 \\
16 \\
17 \\
18 \\
19 \\
20 \\
\end{array}$ & $\begin{array}{l}5 \cdot 0 \\
5 \cdot 5 \\
4 \cdot 0 \\
5 \cdot 0 \\
3 \cdot 5 \\
4 \cdot 0 \\
3 \cdot 0 \\
4 \cdot 5 \\
3 \cdot 0 \\
6 \cdot 0 \\
3 \cdot 0 \\
3 \cdot 5 \\
4 \cdot 5 \\
4 \cdot 0 \\
4 \cdot 0 \\
4 \cdot 0 \\
5 \cdot 5 \\
3 \cdot 0 \\
4 \cdot 5 \\
4 \cdot 0 \\
\text { Mean pu. }\end{array}$ & $\begin{array}{l}9 \cdot 0 \\
8 \cdot 0 \\
7 \cdot 0 \\
7 \cdot 5 \\
8 \cdot 5 \\
8 \cdot 0 \\
7 \cdot 0 \\
5 \cdot 5 \\
6 \cdot 5 \\
7 \cdot 5 \\
8 \cdot 0 \\
7 \cdot 0 \\
9 \cdot 0 \\
8 \cdot 0 \\
8 \cdot 0 \\
6 \cdot 0 \\
8 \cdot 5 \\
7 \cdot 5 \\
9 \cdot 0 \\
8 \cdot 5 \\
\text { ary dilatation } 3 \cdot 6\end{array}$ & $\begin{array}{l}4 \cdot 0 \\
2 \cdot 5 \\
3 \cdot 0 \\
2 \cdot 5 \\
5 \cdot 0 \\
4 \cdot 0 \\
4 \cdot 0 \\
1.0 \\
3 \cdot 5 \\
1.5 \\
5 \cdot 0 \\
3 \cdot 5 \\
4 \cdot 5 \\
4 \cdot 0 \\
4 \cdot 0 \\
2 \cdot 0 \\
3 \cdot 0 \\
4 \cdot 5 \\
5 \cdot 5 \\
4 \cdot 5 \\
\text { SD } 1.2) \mathrm{mm}\end{array}$ & $\begin{array}{l}5 \cdot 5 \\
5 \cdot 0 \\
4 \cdot 5 \\
5 \cdot 0 \\
3 \cdot 0 \\
4 \cdot 0 \\
3 \cdot 0 \\
4 \cdot 0 \\
3 \cdot 5 \\
6 \cdot 0 \\
3 \cdot 0 \\
4 \cdot 0 \\
4 \cdot 5 \\
4 \cdot 0 \\
4 \cdot 0 \\
4 \cdot 0 \\
5 \cdot 0 \\
3 \cdot 0 \\
5 \cdot 5 \\
4 \cdot 0 \\
\text { Mean pu } \\
\text { (SD 1.2) }\end{array}$ & $\begin{array}{l}9 \cdot 5 \\
8 \cdot 0 \\
8 \cdot 5 \\
7 \cdot 5 \\
7 \cdot 5 \\
7 \cdot 5 \\
7 \cdot 0 \\
6 \cdot 0 \\
6 \cdot 5 \\
7 \cdot 0 \\
7 \cdot 5 \\
7 \cdot 0 \\
8 \cdot 0 \\
8 \cdot 0 \\
8 \cdot 0 \\
8 \cdot 5 \\
8 \cdot 5 \\
7 \cdot 0 \\
8 \cdot 5 \\
8 \cdot 5 \\
\text { rry dilatatio } \\
\end{array}$ & $\begin{array}{l}4 \cdot 0 \\
3 \cdot 0 \\
4 \cdot 0 \\
2 \cdot 5 \\
4 \cdot 5 \\
3 \cdot 5 \\
4 \cdot 0 \\
2 \cdot 0 \\
3 \cdot 0 \\
1 \cdot 0 \\
4 \cdot 5 \\
3 \cdot 0 \\
3 \cdot 5 \\
4 \cdot 0 \\
4 \cdot 0 \\
4 \cdot 5 \\
3 \cdot 5 \\
4 \cdot 0 \\
3 \cdot 0 \\
4 \cdot 5 \\
\cdot 7\end{array}$ \\
\hline
\end{tabular}

each of the tear menisci. This can briefly increase to a maximum of $30 \mu \mathrm{l} .{ }^{4}$ Shell ${ }^{4}$ has estimated that $80 \%$ of the volume of a $50 \mu \mathrm{l}$ drop rapidly passes down the nasolacrimal duct, so that most of the administered drug has minimal contact time with the eye and passes to the highly vascular nasal mucosa, where it can be systemically absorbed. Absorption across the conjunctiva and nasal mucosa avoids first-pass metabolism in the liver and results in peak levels only 10 minutes after topical administration. ${ }^{5}$

The accepted safe dose of intravenous phenylephrine is $1.5 \mathrm{mg}^{3}$ A $50 \mu \mathrm{l}$ drop of phenylephrine contains $5.0 \mathrm{mg}$, so that systemic absorption can easily lead to dangerously high levels, particularly when multiple drops are given. Fortunately the volume delivered by Minims is not the $50 \mu \mathrm{l}$ which is widely quoted, but only $30 \mu \mathrm{l}$. Nevertheless there is still further scope for reduction in drop size, as the $10 \mu \mathrm{l}$ drops were just as effective as $30 \mu l$ drops.

Reducing drop size may increase bioavailability of the medication. Patton and Robinson ${ }^{6}$ have shown that $5 \mu \mathrm{l}$ of $1.92 \times 10^{-2} \mathrm{M}$ pilocarpine produced the same tear film concentration as $25 \mu \mathrm{l}$ of $1.0 \times 10^{-2} \mathrm{M}$ despite containing only $38 \%$ as much pilocarpine. This could be because the smaller drops stimulate less lacrimation and so increase contact time. One of the limiting factors in reducing the size of eyedrops is ease of administration. It was difficult to ensure that only one drop fell on to the eye from the $22 \mathrm{G}$ cannula, and the lack of awareness that a drop has been delivered could cause problems.

A thin-walled cannula of the type used in this study would be quite unsuitable for commercial use, as it would be damaged too easily, and it tends to deliver a jet of fluid if the bottle or Minim is squeezed too hard. Conventional eye dropper tips which have an inner resistance aperture to ensure that single drops are delivered, and a relatively thick wall in relation to the diameter of the lumen, can be modified to deliver consistently smaller drops. ${ }^{78}$

Reducing the volume of eyedrops is not the only way to reduce systemic absorption: punctal plugging, nasolacrimal duct compression, and lid closure after eyedrop instillation are all effective. ${ }^{910}$ However, these techniques require prolonged commitment from medical staff and exceptionally well motivated patients. They would in any case be even more effective after administration of a small drop, since the cornea across which absorption into the eye occurs occupies only $17 \%$ of the ocular surface area,${ }^{11}$ so that there is still a significant area through which systemic absorption can occur.

1 Fraunfelder FT, Scafadi M. Possible adverse effects from topical ocular $10 \%$ phenylephrine. A $m$ f Ophthalmol 1978; 4 447-53.

2 Heath P, Geite CW. Use of phenylephrine hydrochloride (neosynephrine hydrochloride) in ophthalmology. Arch Ophthalmol 1949; 41: 172 .

3 Yoon-Kee Lai. Adverse effect of intraoperative phenvlephrine 10\%: case report. Br f Ophthalmol 1989; 73: +68-9.

4 Shell JW. Pharmacokinetics of topically applied drugs. Surv Ophall Pharmacokinetics of

5 Kumar V, Schoenwald DS, Chien BS, Packer AJ, Choi WW. Systemic absorption and cardiovascular effects of phenyephrine drops. Am f Ophthalmol 1985; 99: 180-4.

6 Patton TF, Robinson JR. Quantitative precorneal disposition of topically applied pilocarpine nitrate in rabbit eyes. F Pharm Sci 1976; 65: 1295-9.

7 Brown RH, Hotchkiss ML, Davis BE. Creating smaller eyedrops by reducing eyedropper tip dimensions. Am $\mathcal{F}$ Ophthalmol 1985; 99: 460-4.

8 Brown RH, Lynch MG. Design of eyedropper tips for topical beta blocking agents. Am $\mathcal{F}$ Ophthalmol 1986; 102: 123-4.

9 Zimmerman TJ, Kooner KS, Kandarakis AS, Ziegler LP. Improving the therapeutic index of topically applied ocular Improving the therapeutic index of topicall

10 Huang TC, Lee DA. Punctal occlusion and topical medications for glaucoma. Am $\mathcal{F}$ Ophthalmol 1989; 107: 151-5.

11 Watsky MA, Jablonsky MM, Edelhauser HF. Comparison of conjunctival and corneal surface areas in rabbits and humans. Curr Eye Res 1988; 7: 483-7. 